\title{
Commons-Based Peer Production in the Work of Yochai Benkler
}

\author{
Evangelos Papadimitropoulos
}

Research Affiliate, Free University of Amsterdam, vagpap78@hotmail.com

\begin{abstract}
Yochai Benkler defines commons-based peer production as a non-market sector of information, knowledge and cultural production, which is not treated as private property but as an ethic of open sharing and co-operation, and is largely enhanced by the Internet and free/open source software. This paper makes the case that there is a tension between Benkler's liberal commitments and his anarchistic vision of the commons. Benkler limits the scope of commons-based peer production to the immaterial production of the digital commons, while paradoxically envisaging the control of the world economy by the commons. This paradox reflects a deeper lacuna in his work, revealing the absence of a concrete strategy as to how the immaterial production of the digital commons can connect to material production and control the world economy. The paper concludes with an enquiry into some of the latest efforts in the literature to fill this gap.
\end{abstract}

Keywords: Benkler, commons-based peer production, digital commons, Bauwens and Kostakis, design global-manufacture local

Acknowledgement: I deeply and wholeheartedly thank the reviewers for their time and effort to constructively comment on my paper.

\section{Introduction}

Yochai Benkler has been one of the most prominent scholars to elaborate on a novel mode of production that emerged in the last decades in stark contrast to both state and for-profit production. His work has introduced commons-based peer production in the social sciences as a non-market sector of information, knowledge and cultural production, not treated as private property but as an ethic of open sharing and cooperation. Benkler has focused particularly on the Digital Commons of the Internet and free/open source software (FOSS).

Benkler's work has had a great impact on FOSS development and contributed enormously to the dissemination of the term "commons-based peer production" among scholars, citizens and activists in the last decades. However, there are scarcely any papers in the literature examining his work in depth.

This article is an attempt to shed light on Benkler's work and commons-based peer production in general. My main argument here is that Benkler limits the scope of commons-based peer production to the immaterial production of the digital commons, while paradoxically envisaging the control of the world economy by commonsbased peer production. Therefore, a tension arises between Benkler's liberal commitments and his anarchistic visions, revealing a deeper lacuna in his work concerning the absence of a concrete strategy as to how the immaterial production of the digital commons can replicate into material production and thereby control as much as possible of the world economy. 
The structure of this article is as follows. Firstly, I outline the contours of commonsbased peer production. Secondly, I develop Benkler's theoretical explanation of commons-based peer production. Thirdly, I analyse the trade-offs between commons-based peer production, markets and managerial hierarchies. Fourthly, I briefly sketch out Bauwens and Kostakis's work, which has the ambition to resolve the tension in Benkler's work and connect the immaterial production of the digital commons to material production on the "Design Global - Manufacture Local" model. I conclude that in both Benkler's and in Bauwens and Kostakis's work there is a significant lack of the political dimension, which is necessary to uncover the challenges lying at the crossroads of technology, society and politics.

\section{The Contours of Commons-Based Peer Production}

Yochai Benkler's work builds on the technological innovations of the 21st century in the networked information economy with the aim to introduce a novel normative framework for refiguring civil collaboration with respect to the market-state nexus. He demonstrates a model of networked pragmatism/anarchism, emerging by virtue of information and communication technologies. Networked pragmatism/anarchism is based on the decentralised self-management of information, knowledge and cultural production supported by the Internet and FOSS. The concept of decentralised selfmanagement is not novel in economics and political theory, since it is reminiscent of the work of numerous thinkers, related to diverse and often disparate strands of political thought ranging from anarchocapitalism and anarchosyndicalism to autonomous Marxism and radical republicanism. What is novel in Benkler's work is the technological substratum of a liberal critique of managerial hierarchies and market limitations on individual freedom, participatory democracy and justice, ameliorated today by the emergence of a new organisational model termed "commons-based peer production".

Benkler defines commons-based peer production as a non-market sector of information, knowledge and cultural production, not treated as private property but as an ethic of open sharing, self-management and co-operation among peers who have access to fixed capital such as software and hardware (Benkler 2006, 59-90). Commons-based peer production consists in open contributory networks of distributed tasks, set and executed by groups online in a decentralised and autonomous fashion.

The term 'commons' refers to a particular institutional form of structuring the right to access, use and control resources, which differs significantly from the current property regime dominant both in managerial hierarchies and markets. The distinctive features of the commons are: (1) decentralised self-governance through utilisation of participatory, meritocratic (do-ocracy) and charismatic rather than proprietary or contractual models; (2) the centrality of non-monetary motivations; and (3) the permeation of state and firm boundaries (Benkler et al. 2015, 2-3; Benkler 2016a, 2).

Benkler divides commons into four types according to two parameters. The first parameter is whether commons are open or limited access. Examples of openaccess commons are airwaves, highways, parks, language, information, knowledge and culture. Examples of limited-access commons include those famously documented by Elinor Ostrom, who was awarded the Nobel Prize in economics in 2009 for having examined numerous successful cases of self-managed common pool resources (i.e. forests, pastures, fisheries, irrigation fields), manifested for centuries across the globe from the USA and Switzerland to Spain, Nepal and Indonesia (Ostrom 1990). 
The second parameter is whether commons are regulated or unregulated. Limitedaccess commons are regulated, whereas open-access commons can be both regulated and unregulated depending on the content and context. For instance, access to information is limited when enclosed by intellectual property rights. But, arguably, this classification is circular and, therefore, problematic on purely logical grounds, since the criterion of classification (regulation/deregulation) is itself included in the first parameter. Thus, it is itself classified. Moreover, it does not take into account the rival and non-rival/anti-rival characteristics of the commons ${ }^{1}$.

For this reason, I propose a different classification. According to the content, there are two main types of commons: material/rival (natural resources) and immateri$\mathrm{al} /$ non-rival/anti-rival (language, information, knowledge, culture). Depending on the context, then, the commons can be regulated or unregulated. By content I mean here the 'endogenous' essence of things in general (i.e. data, molecules, words, etc.), whereas by context I refer to the 'exogenous' human framing of things (i.e. laws, design, customs, etc. $)^{2}$. This classification avoids circularities inasmuch as content and context do not identify. Different contexts can apply to the same content and vice versa. For example, information - when not enclosed by intellectual property rights is a common good ${ }^{3}$. Similarly, Massimo De Angelis argues:

The limit to what can be considered a common good is entirely contextual and political, depending on the political boundaries, imaginative capability and involvement in doing in commons that a community can give itself (De Angelis 2017, 63).

De Angelis has correctly highlighted the relational/contextual character of the commons, that is, the social relations of commoning and governing the commons that give to a good the meaning of a common good (2017, 62-64).

Benkler argues that not all peer production qualifies as commons-based production. The term "commons-based" denotes the absence of exclusive property:

The salient characteristic of commons, as opposed to property, is that no single person has exclusive control over the use and disposition of any particular resource in the commons. Instead, resources governed by commons may be used or disposed of by anyone among some (more or less well-defined) number of persons, under rules that may range from 'anything goes' to quite crisply articulated formal rules that are effectively enforced (Benkler 2006, 61).

Benkler notes that the term "peer production" signifies a subset of commons-based production practices, which "[...] refers to production systems that depend on individual action that is self-selected and decentralized, rather than hierarchically assigned" (Benkler 2006, 62). Benkler further makes the distinction between commons-based

\footnotetext{
${ }^{1} \mathrm{~A}$ good is rival if its use by one person subtracts from the total available to others. For example, a fish or an apple is a rival good. A good is non-rival if the cost of reproducing an additional unit is near zero. For example, knowledge and information - when not enclosed by intellectual property rights - are non-rival goods. A good is anti-rival if it becomes more valuable as more people consume it. For example, the more people use a language or a software, the more valuable it becomes. For more see De Angelis (2017, 29-74).

2 This classification is just a schematic one since content (re)formulates context and vice versa.

${ }^{3}$ I do not engage here in the distinction between common and public goods, which is an issue of a much broader political controversy. For more on that see Quilligan (2012).
} 
peer production (digital commons in his case) and firm-hosted peer production (peer production integrated into corporations such as IBM, Red Hat and Google). The latter refers also to online business models of the so-called 'sharing' and gig economy (i.e. Uber, Airbnb, Kickstarter, Taskrabbit and Upwork).

The quintessential instance of commons-based peer production in the digital commons is free and open source software. FOSS was invented in 1984 by Richard Stallman, who introduced the GNU General Public License (GPL) as a legal hack in the traditional copyright system, allowing programmers to freely access, copy, modify and distribute software on the same copyright terms. Put differently, the core defining feature of FOSS is the renouncing of exclusive proprietary control over the software in which one has copyright (Benkler 2013, 221). Far from meaning the abolition of copyright, the FOSS establishes a 'copyleft' system on the basis of the traditional copyright system. Building on top of the GPL, Linus Torvalds in 1991 developed the Linux operating system, which crystallised a model of collaborative production of software developers based on volunteering and sharing.

According to Michel Bauwens and Vasilis Kostakis (2014), FOSS sustains a sort of cyber-communism operating at the very heart of capitalism, where everybody can contribute and share. However, the most common political interpretations of FOSS tend to be libertarian rather than communist. Others have pointed to the political agnosticism of FOSS developers ${ }^{4}$.

Non-proprietary, voluntaristic, self-organised practices account for standardsetting for the Internet itself (TCP/IP, HTML) (Benkler 2013, 214). FOSS produces some of the core software utilities that run the Web - servers, emails, scripting, applications, plugins. The FOSS accounts for $70 \%$ of web servers running on the Apache web server; more than $70 \%$ of web browsers (Firefox, Chrome); server-side programming languages (PHP); content management systems (Wordpress, Joomla, and Drupal have more than $70 \%$ of servers); smartphone operating systems; enterprise software (Google, Amazon and CNN.com run their servers on the GNU/Linux operating system; $40 \%$ of firms engaged in software development contribute to the FOSS development). In short, roughly half of the Internet runs on FOSS.

The digital commons of FOSS development, however, is not the only instance of commons-based peer production. The latter expands into large-scale collaboration in the networked information environment. It ranges from scientific research and knowledge commons to non-professional information and cultural production taking place on entertainment sites and in grassroots movements, communities and interpersonal relationships (i.e. families and friendships).

The digital commons in particular expand from FOSS development to distributed content production and sharing of processing, storage, and communications platforms. Examples of distributed content production are the Nasa Clickworkers, Wikipedia, Kuro5hin, Multiplayer Online Games, Open Directory Project, Slashdot, and Project Gutenberg. Examples of sharing of processing, storage, and communications platforms are Napster, Gnutella, SETI@home, Skype, Bitcoin, and WiFi. The digital commons have proliferated globally in the last decade to an extent that largely escapes Benkler's own work. Recent research has documented hundreds of cases currently in progress (De Filippi and Tréguer 2015a; 2015b; De Filippi 2015a; 2015b; De Filippi and Troxler 2016) ${ }^{5}$. Arguably, blockchain technology also has the potential to

\footnotetext{
${ }^{4}$ See Coleman (2004); Raymond (1999); Stallman (2002).

${ }^{5}$ For more see http://directory.p2pvalue.eu.
} 
support both online and offline decentralised collaboration (De Filippi and Hassan 2016).

Nevertheless, Benkler is somewhat ambivalent when it comes to examining the overall scope of commons-based peer production. He almost overwhelmingly limits commons-based peer production to information, knowledge and cultural production, arguing that decentralised social production cannot apply to large-scale material goods like the manufacturing of automobiles, steel or airplanes. Commons-based peer production, he claims, is not always the most efficient model even for the production of information, knowledge and culture. It can be prone to failure because of insufficient contributions or due to large parts of the population being sceptical about non-market models of provisioning goods (Benkler 2013, 244). The crux of his argument is that commons-based peer production has certain advantages over the state, markets or firms in identifying and allocating human capital and creativity (Benkler $2002 a, 381)$. Yet commons-based peer production will not replace state and market operation. It can only improve their imperfections by establishing a third pillar of a more autonomous civil society.

Paradoxically, Benkler states that it is worthwhile to continue building more of the successes of commons-based peer production and try to control as much of our world as possible with its mutualistic modality of social organisation (Benkler 2013, 216). In a liberal twist, he holds that the basic problem for a political theory dealing with the emergence of commons-based peer production is the infeasibility of removing power from even a reasonably well-functioning democratic state and market economy (Benkler 2013, 242).

Yet if it is infeasible to remove power from the state and the market, how could commons-based peer production control as much of our world economy as possible? Benkler himself wonders how generalisable the commons can be beyond constituting a mere hack, beneficial only under particular circumstances and overlaid on the background of a liberal state with a reasonably liberal property and market system (Benkler 2013, 242). One can, therefore, identify a tension between Benkler's liberal commitments and his anarchistic visions of the commons. By liberal commitments I mean the normative political framework adopted by Benkler that refers to the defence of the moral values of negative freedom, individual autonomy and pluralism, as embedded in modern capitalist markets and state democracies. The anarchistic visions of Benkler seemingly contravene his liberal commitments inasmuch as he advocates the expansion of propertyless, decentralised and stateless commons-based peer production. Benkler is being realistic by stressing the current premature development of commons-based peer production. He draws our attention to the fact that commons-based peer production is still in its infancy and suffers from several imperfections. Further qualitative and quantitative studies on peer production would yield better outcomes on how central or peripheral a phenomenon this is (Benkler 2002a, 444). At the same time, he is utopian by pushing further the boundaries of commonsbased peer production to control as much as possible of the world economy. However, he does not illustrate a clear path towards this transition. Prior to delving deeper into this ambivalence, it is essential to examining the economic and social enablers of commons-based peer production.

\section{The Economic and Social Enablers of Commons-Based Peer Production}

In providing a theoretical explanation of commons-based peer production, Benkler builds on a large body of work stemming primarily from the social sciences. To begin with, he intentionally positions himself inside the mainstream of economic theory to 
be consonant with current discussions of law and policy. He thus uses Ronald Coase's transaction costs theory to argue that peer production could, under certain circumstances, be a less costly institutional form than either markets or hierarchical organisations:

We would say that when the cost of organizing an activity on a peered basis is lower than the cost of using the market or hierarchical organization, then peer production will emerge (Benkler 2002a, 403).

Benkler further draws on Manuel Castells's work to argue that commons-based peer production is co-emergent with a networked information economy that replaces industrial information economy on the grounds of four basic inherent features: (1) the primary inputs and outputs of production in the networked information economy, unlike the industrial economy, are open access commons - existing information, knowledge and culture; they are non-rival/anti-rival goods, since their marginal cost of reproduction is near zero; (2) there are cheap physical capital costs (cheap processor-based computer networks) coupled with the digitisation of information production; (3) the architecture of the Internet allows for the decentralisation and modularity of human computer interaction; in addition, human creativity is more central and variable in the information production than in other modes of production, meaning that is more diverse, flexible and, therefore, potentially more effective; (4) the dramatic decline in communication costs.

Transaction cost theory thus testifies to low entry barriers to information, knowledge and cultural production:

The dramatic decline in the cost of the material means of producing and exchanging information, knowledge, and culture has substantially decreased the costs of information expression and exchange, and thereby increased the relative efficacy of non-market production. When these facts are layered over the fact that information, knowledge, and culture have become the central highvalue-added economic activities of the most advanced economies, we find ourselves in a new and unfamiliar social and economic condition. Social behavior that traditionally was relegated to the peripheries of the economy has become central to the most advanced economies. Non-market behavior is becoming central to producing our information and cultural environment. Sources of knowledge and cultural edification, through which we come to know and comprehend the world, to form our opinions about it, and to express ourselves in communication with others about what we see and believe have shifted from heavy reliance on commercial, concentrated media, to being produced on a much more widely distributed model, by many actors who are not driven by the imperatives of advertising or the sale of entertainment goods (Benkler 2006, 56).

Transaction costs theory alone cannot explain the rise of commons-based peer production. The latter is additionally marked by a diversity of non-monetary motivations, the centrality of which poses a puzzle for conventional economics, since it contradicts its main behavioural model of the self-interested maximiser.

Conventional wisdom dating back to Aristotle and Hobbes has emphasised the problem of collective action in economics. Under the "Tragedy of the Commons" critique, famously introduced by Hardin (1968), fall the motivation and organisation problems of the commons. Hardin called us to picture a pasture open to all, in which 
each herder acts as a self-interested actor, aiming to maximise his gain by adding more and more animals for grazing. This eventually results in overgrazing and pasture depletion. Hardin's metaphor of the grazing commons has been formalised as a prisoner's dilemma game that expands accordingly in all situations where the "tragedy of the commons" applies. Today, the so called "tragedy of the commons" could also be applicable to the Internet (spectrum usage) and the digital commons ${ }^{6}$.

Traditional responses to this problem combine Hobbes's Leviathan approach central command and control - with Smith's invisible hand of the market that matches supply and demand by means of property rights and price signals. Cycles of a Leviathan state and the invisible hand of the market intersect historically in the 'moving' peripheries of managerial hierarchies and markets, taking for granted the selfishness of mankind.

Organisational sociology suggests that effective organisations succeed through hierarchical control and management (Weber 1978). Neoclassical economic explanations of behaviour are based on the assumption of a fundamentally self-interested rational actor motivated by financial and other incentives (Lowenberg 1990). Compensation and contracts are, therefore, necessary for individuals to exchange the valuable products of their work and thus maximise their subjective utility.

On the flipside, motivation is considered to be lacking in commons-based peer production, since no one will invest time, money and energy in a project if they cannot appropriate its benefits. Moreover, power to organise collaboration in the use of the resource is absent. Therefore, organisation will be insufficient and collaboration will fail. How are we then to explain the success of numerous cases of natural and digital commons, highlighted by Ostrom and Benkler respectively?

Ostrom proved Hardin wrong by illustrating hundreds of cases of common pool resources self-managed by user communities for centuries in accordance with welldefined rules and norms. After extensive field observation, she came up with a set of design principles governing limited-access commons, such as the demarcation of clear boundaries, the matching of rules with local needs and conditions, the modification of rules by users themselves, the monitoring of resources and the imposition of sanctions on free-riders. Thus, Ostrom's empirical work offers important insights on how formal and informal norms can structure collaboration along the lines of nonproperty-based schemes. Yet her studies focus on relatively limited groups of participants, rather than examining the sustainability of large-scale non-proprietary peer production projects such as the digital commons (Benkler 2002a, 378). In addition, conventional economics consider Ostrom's limited-access commons developing at the periphery, thus failing to touch on the core of the world economy, in which the model of the self-interested maximiser prevails.

Benkler shows that this does not hold true for the digital commons, which account for a considerable part of the actual economy. FOSS, in particular, is an economically significant institutional and organisational strategy:

As of January of 2013, Apache held a $55 \%$ market share, Microsoft $17 \%$; nginx, an alternative FOSS platform, 13\%; Google's servers for its own machines, 4\%; and the remainder was held by platforms bunched as "other". (Netcraft Websurvey 2013). Server side scripting languages are the primary languages used for programming functions of the Web. PHP, an open source language, is used by $78 \%$ of websites, while Microsoft's ASP.Net holds the

\footnotetext{
${ }^{6}$ For more see Lessig $(2006,273)$.
} 
remaining 20\%; most of remaining languages, like Ruby or Python, are also open source. (W3Techs 2013). Web Browser statistics are less clearly in favor of open source. Historically, Microsoft's Internet explorer held over $95 \%$ of the market after it squeezed Netscape Navigator out of the market (illegally, according antitrust adjudications in both the US and EU). Netscape then spun out Navigator to a non-profit, the Mozilla foundation, as FOSS. Overtime, Firefox gradually captured market share over the 2000s, and in 2008 Google released Chrome, and at the same time a parallel, FOSS project, Chromium. As of January 2013, competing methods identify IE as either having $55 \%$ of the desktop browser market or 31\%; and Chrome and Firefox having either 18\% and $20 \%$, respectively, or $36 \%$ and $22 \%$ respectively. (ZDNET 2013). By a different measure, almost $40 \%$ of firms engaged in software development reported spending development time on developing and contributing to FOSS software. (Lerner and Schankerman 2010) [...] Wikipedia is by far the most successful, largest, and most diverse peer production project. The subject of several books and over 5,000 articles, Wikipedia is among the top 6 to 8 sites in the world, and has become the basic knowledge utility of networked life, alongside Google search [...] Online, in a range of specific product areas, business models that deepen on peer production have outcompeted businesses that depend on more traditional, price-cleared or firm-centric models of production. Flickr, Photobucket, and Google Images, all of which are peer production platforms capable of delivering stock photography, have overshadowed Corbis, the primary form using the traditional model in this field. Youtube, Google video, and Vimeo are all more highly ranked as online video sites than the proprietary models of Hulu, Vevo, or even Netflix (though Netflix, the most widely used among these, is roughly equal to Vimeo). TripAdvisor is more popular than Lonely Planet, Fodor's, or Frommers in travel guides. Yelp, in restaurant reviews. In all, organizations, both for-profit and non-profit, who have found ways of organizing their core production function on a peer production model have thrived in the networked environment often overcoming competition from traditional market- and firm-based models. (Benkler 2016b, 6-7)

It is evident, then, that the technological innovations of the 21 st century in information, knowledge and cultural production has given the opportunity to individuals, groups and firms to produce a wide range of commercial and non-commercial products and services, using a variety of strategies, which rely on exclusive to nonexclusive property rights applied both to market and non-market models. However, this is far from establishing the hegemony of commons-based peer production, as Benkler paradoxically envisages. Rather, it testifies to the co-optation of FOSS development by capital; that is, the corporate appropriation of peer production for the purpose of profit maximisation (Birkinbine 2018; Broumas 2017).

As regards the non-monetary motivations inherent in FOSS development, Benkler argues that there is no puzzle to solve, since the theoretical framework adopted to explain behaviour by conventional economics is simply flawed. The widely held assumption that self-interest motivates behaviour, that managerial hierarchies and markets are the best ways to produce goods, that property rights and contracts are sine qua non for organising production, are not equally applicable to information (Benkler $2006,41)$. FOSS forces us to re-evaluate these claims by placing intrinsic and social motivations, rather than material incentives, at the core of innovation; by questioning 
the centrality of managerial hierarchies and markets to the innovation process; and by challenging the centrality of property, as opposed to the interaction of property and commons (Benkler 2016a, 1).

The incentives problem raised by neoclassical economics has been extensively addressed by the literature today with regards to FOSS development (Lakhani and von Hippel 2003; Lerner and Tirole 2002; von Krogh et al. 2003). Lerner and Tirole have catalogued a series of intrinsic and social motivations in FOSS production that testify to some combination of hedonic gain and indirect appropriation: the playful joy of creation, reputation, social-psychological rewards, and increases in human capital are some of the indirect benefits for those participating in commons-based peer production (Lerner and Tirole 2002). Given that two thirds of the revenues of the software industry are service-based, the skills indirectly appropriated in free software development can be directly redeemed in proprietary projects (Benkler 2002a, 424425). This goes to show, however, that extrinsic motivations combine with intrinsic motivations rather than getting overshadowed by the latter.

Benkler draws on the work of Eric von Hippel $(1988 ; 2005)$ to further argue that innovation is a collective process of knowledge production and learning. Von Hippel has introduced a model of user-driven innovation, both online and offline. His theoretical and empirical work has shown how the model of user innovation has been integrated into the business model of innovative firms even in sectors far removed from either the network or from information production - like designing kite-surfing equipment or mountain bikes. But, still, this is another version of firms co-opting user innovation rather than democratising innovation, as von Hippel claims. Benkler seems thus to overstate the collective and non-monetary features of Commons-based peer production.

Benkler $(2016 \mathrm{a}, 8)$ refers also to extensive empirical work carried out across a vast array of disciplines in the last decades, which shows that humans exhibit diverse pro-social motivations, responding to a range of non-material, non-self-interested motivations, from reciprocity to group identity through, in some cases, altruism (Camerer and Fehr 2004; Fehr and Gintis 2007; Ostrom 1990). Experimental and observational data has exhaustively documented that the effects of standard economic incentive tools such as material rewards and punishments are not only inseparable from but, in some cases, detrimental to the sum of motivations across the target population (Bowles and Polania-Reyes 2012; Bowles and Hwang 2008; Frey and Jegen 2001; Frey 1997). Not only is there a tension between material rewards and pro-social motivations, but also between diverse pro-social motivations themselves. Individuals are driven by motivations that differ from each other in mixing motivational drivers. Peer production therefore faces a critical design challenge for balancing out motivations that has not yet been addressed by commons-based peer production. Monetary motivations still prevail by necessity. The need for most parts of society to pay the bills and make a living in a capitalist economy usually overtakes non-monetary pro-social motivations.

To address the dependence of the commons on capital and the subsequent cooptation of the former by the latter, De Angelis (2017) has introduced the ideas of "boundary commoning" and "structural coupling", that is, the expansion of the commons through internal cooperation and external deals that each allow the former to reproduce within capitalism and reach a critical mass on a mission to bring about a "middle class explosion". Similarly, Bauwens and Kostakis (2014) have introduced the notion of the capitalist commons, that is, commons developing in co-operation with a friendly capitalism willing or forced to adjust to commons-based peer produc- 
tion in the long run. I will examine the pros and cons of both proposals in the last section of this article.

Back to Benkler: his main intent is not merely to highlight the diversity of prosocial motivations inherent in commons-based peer production, but to question the current dominance of neoliberalism by dispelling the myth of universal selfishness and progressing the commons into an autonomous and sustainable mode of production. His basic argument is that the Internet and FOSS bring to the fore the cooperative element of human nature, occasionally counterweighting self-interested motivations. To back up this claim, he brings up striking evidence from evolutionary biology and the social sciences, illustrating the shift in the scientific understanding of human rationality from the model of the self-interested maximiser, driven by competition and separable motivations, to the model of homo socialis, driven by co-operation and diverse pro-social motivations (Benkler 2011b). Rationality does not always translate into self-interest, since humans often rationally pursue non-self-interested goals.

His overstatements excluded, Benkler is right to claim that our organisational models of society, from the state and firms to markets and institutions, are based on a wrong anthropological type. A new field of co-operative human systems design is needed to account for the diversity of motivations and for the non-additivity of material with social motivations. To further envisage this transition it is essential to compare neoliberalism with commons-based peer production in terms of the markers of uncertainty and complexity.

\section{Uncertainty and Complexity: Trade-Offs Between Commons-Based Peer Pro- duction, Managerial Hierarchies and Markets}

Uncertainty (whether with unknown or known probabilities) and complexity (whether linear stochastic or non-linear) pose major problems for both neoclassical economics and new institutional models, because agents, resources and projects are highly diverse and interconnected, with the interactions among them becoming enormously complex to the point that small differences in initial conditions can dramatically alter outcomes over time (Benkler 2002a, 406-415).

To further demonstrate this viewpoint, Benkler juxtaposes neoliberalism with commons-based peer production in terms of information-processing systems. His main argument is that commons-based peer production, under certain circumstances, processes information better than neoliberalism on conditions of complexity and uncertainty (Benkler 2002a, 406). Information here is used by Benkler in the technical sense of reducing uncertainty.

In broad terms, neoliberalism refers to the doctrine that markets and firms unfettered by state intervention better allocate resources (Brown 2015; Springer 2012). Neoliberalism is predicated on the neoclassical economics assumption that collective action fails to manage economy owning to the uncertainty and complexity inherent in information-processing, rendering coordination and planning impossible (Reisman 1990). Complexity and uncertainty impede collective action - the prisoner's dilemma game renamed. Only pricing in markets produces good information and coordination. Clear property rights and free markets are necessary and sufficient for welfare.

Ostrom, on the other hand, has demonstrated that hierarchies, prices and property are 'lossy' in processing information under conditions of uncertainty and complexity. The plethora of limited-access commons thriving across the globe over centuries indicate that there is no single model of ideal organisation. There is vast diversity consistent with polycentricity. In plenty of cases, local knowledge and practices out- 
perform rationalised models, both bureaucratic and abstract markets. Redundancy, resilience and experimentation on the freedom to co-operate produce better practices. Therefore, property limits exploration.

Benkler expands this mode of production on the Internet to sketch out the move from tightly-coupled systems managed by well-designed mechanisms to looselycoupled systems based on experimentation and ethical engagement. Innovation and information production do not emerge as much from strong intellectual property rights, as held by conventional wisdom. Information, knowledge, and culture are produced in diverse ways that render exclusive property rights - like patents, copyrights, and similar regulatory constraints on the use and exchange of information - detrimental to innovation and information production (Benkler 2006, 48). Innovation comes mostly from a mixture of non-market sources - both state and non-state - and market actors whose business models do not strictly depend on the regulatory framework of intellectual property (Benkler 2006, 39). Economists have long emphasised the costs of patents to information production, given the public-goods nature of information (Arrow 1962). Strong patent protection increases the costs that current innovators have to pay on existing knowledge more than it increases the benefits of appropriating the value of their own contributions (Benkler 2006, 38-39). Strong intellectual property leads to commercialisation, concentration, and homogenisation of information production rights, thus stifling innovation (Benkler 2002b).

Commons-based peer production relies instead on more open, diverse and flexible copyright options. Commons-based licensing comes in a variety of forms. Ostrom makes the distinction between exclusive private property rights and a bundle of rights that are most relevant to the use of common-pool resources, such as the right to access (enter a defined physical area and enjoy non-subtractive benefits), withdraw (obtain resource units or products), manage (regulate internal use patterns), and exclude and alienate (sell or lease management and exclusion rights) (Ostrom and Hess 2007, 11). In Ostrom's account, property rights define authorities over a range of possible actions. In other words, property accounts for a sort of power over nature and others.

The General Public License (GPL) expands some of the features of limitedaccess commons into the digital commons by allowing software to be freely accessed, copied, modified and distributed on the same terms. The GPL is widely used in free and open source software in a variety of versions.

Creative Commons (CC) licensing comes also in a variety of types: (1) the attribution license (CC-BY) permits the copy, remix and redistribution of the material (not limited to software) for any purpose, even commercially, provided that credit is given; (2) the attribution - non-commercial (CC-BY-NC) license permits the copy, remix and redistribution of the material for non-commercial purposes, provided that credit is given; (3) the attribution - share alike (CC-BY-SA) license permits the copy, remix and redistribution of the material for any purpose, even commercially, provided that credit is given and any modification is distributed under the same license; (4) the attribution - non-derivatives (CC-BY-ND) license allows only original copies to be distributed, provided that credit is given.

Thus, the idea that property (as opposed to a mixed infrastructure of property and commons) is the foundation of growth is due for a major revision (Benkler 2006, 9). Commons-based licensing does not entail the complete rejection of the property model but rather the reimagination of it. Property and contractual relations are just one set in an institutional toolkit. Commons-based peer production thus translates into a diversity of institutional forms and motivations. Commons-based peer produc- 
tion can be individual or collaborative, commercial and non-commercial. The individual can be both part of and apart from the collective. Peer production does not displace market actors, but increases the diversity of actors, motivations and transactional forms. It basically decentralises authority where capacity to act exists, thereby diffusing freedom and power to the many.

From the viewpoint of uncertainty and complexity, peer production brings to the fore an information-processing problem for neoclassical economics, which sustain the economic bedrock of neoliberalism. Markets and firm-based hierarchies aim at attaining "perfect information" by reducing uncertainties agents face in evaluating complex and different courses of action (Benkler 2002a, 408). To solve this problem, markets attach price signals to alternative courses of action, while firms assign different weights to different signals from different agents. Signals should be clear and comparable to determine the most cost-efficient use of the relevant factors of production (agents and resources). Both markets and firms need to specify the object of the signal sufficiently so that property, contract, and managerial instructions codify the attributes of agents, resources and projects in a precise manner. Where the particulars cannot be so codified, different agents, resources and projects cannot be accordingly priced or managed. Pricing, then, provides relatively crude information about actual variability among agents, resources and projects.

The fine-grained, diverse qualities of agents, resources and projects and the subsequent fine-grained differences in input combinations or user interactions account for the impossibility to reach managerial decision or price clearance without significant loss of information, control, and, ultimately, effectiveness (Benkler 2016b, 9). The divergence of the existing modes of production - peer production, markets and firms - from the ideal condition of "perfect information" results in information opportunity costs embedded in each mode accordingly. Benkler thus holds that markets and firms are lossy compared to peer production.

Central to Benkler's hypothesis about the information and allocation gains of peer production is the premise that human creativity is highly variable, individuated and therefore very difficult to standardise in the contracts necessary for either marketcleared or hierarchically-organised production (Benkler 2002a, 409). Human creativity is difficult to qualify/quantify for efficient contracting or management due to the multitude of talent, motivation, experience, availability, and so on. Perfect information is all the more unattainable because of the increased transaction costs inherent in the specification process. Moreover, property and contractual relations render agents and resources 'sticky'. That is, employees are not flexible enough to change information, collaborate and thus co-produce knowledge and innovation.

Peer production can improve on markets and firms by correcting these two failures. Recognising the lossiness and rigidity of markets and firms suggests the information and allocation gains of peer production:

Where the physical capital costs of information production are low and where existing information resources are freely or cheaply available, the low cost of communication among very large sets of agents allows agents to collect information through extensive communication and feedback instead of using information-compression mechanisms like prices or managerial instructions (Benkler 2002a, 413).

Commons-based peer production has particular advantages for identifying and allocating human creativity available to work on information and cultural resources, since 
it relies on decentralised information-gathering and exchange to reduce uncertainty and complexity in information-processing. Information exchange among large sets of agents who use existing information resources cheaply to freely communicate reduces uncertainty as to the likely value of various courses of productive action by creating substantial information and allocation gains. The latter overcome the information exchange costs due to the absence of transaction and coordination costs related to pricing, managerial direction, contractual relations and property rights (Benkler 2002a, 406-412). In sum, compared to peer production, information production in managerial hierarchies and markets is lossy, sticky and costly.

The point here is not merely quantitative. It is not just that more people can participate in production. In essence, it is the quality of participations that creates the information and allocation gains of peer production. Given the uncertainty as to the value of various productive activities and the variability of human creativity vis-à-vis any set of production opportunities, decentralised coordination and continuous communication among the pool of potential producers and consumers can generate better information about the most valuable productive actions and the best human agents available at a given time. This way, peer production has the potential to identify who will best produce a specific component of a project.

Yet peer production will not always be successful or superior to markets and firms. The big issue is whether peer production results in an organised chaos better corresponding to the variability of human capacities, or in a disorganised chaos rendering firms and managerial hierarchies indispensable for resource allocation and social cohesion, and which conditions contribute to either outcome. This is a complex and varied function playing out in a gradation of trade-offs. The primary trade-off is between monetary and non-monetary motivations, breaking down into two basic counterbalancing variables: the degree of information uncertainty and the degree of the capital investment necessary for the realisation of a project. The more routine the tasks, and the more capital-intensive a project is, the more appropriate monetary 'incentives' are to motivating contributions, and, therefore, the bigger the role of markets and firms will be in organising production. The more complex and the less costly or capital-intensive a project is, the more likely to attract non-monetary motivations, and, therefore, the bigger the space for peer production (Benkler 2002a, 403-404).

The primary trade-off between monetary and non-monetary motivations results through different analogies and combinations in two basic forms of peer production: commons-based peer production and firm-hosted peer production. The latter comes in a variety of types. We have already mentioned a number of firms that incorporate peer production and FOSS in their strategies. Peer production also shares several attributes with distributed innovation practices emerging in the last decade on the model of the so-called 'sharing' and gig economy, such as crowdsourcing and online labour markets. But still, Benkler points out that not all firms and online business models necessarily deviate from commons-based peer production. What marks a site as firm-hosted peer production or commons-based peer production is not whether a firm owns the site or the trademark associated with it, but whether contract and property are separated from commons governance and management. When IBM participates in Apache and Google distributes Chromium under a FOSS license, they formally own the code, but they do not have the right to intervene in Commons-based peer production. When the peer editors of Wikitravel disapproved of the policies of the site/trademark owner, Internet Brands, they had the right to leave, take all the content, which was under a creative commons license, and start afresh as WikiVoyage (Benkler 2016b, 5-6). 
Benkler focuses on the examination of commons-based peer production wherein the primary trade-off between non-monetary and monetary motivations breaks down into four additional variables: (1) the scale of peer production; (2) the degree of modularity and granularity; (3) the trade-off between waste and efficiency; (4) the cost of integration.

Commons-based peer production has an advantage over market and firms in large-scale collaborations, which are costly to sustain. It would be extremely costly for a firm to produce Wikipedia or Linux. Moreover, large-scale commons-based production renders the motivations problem trivial, since monetary and non-monetary motivations coexist in non-exclusive ways (Benkler 2002a, 433-434). As Benkler (2002a, 434-435) puts it: "The sustainability of any given project depends, therefore, not on the total cost but on how many individuals contribute to it relative to the overall cost".

Moreover, the sustainability of commons-based peer production depends on the degree to which it can reduce the waste produced from duplication of effort. The problem is solved when duplication of effort produces more efficiency than waste. In that case, redundancy, that is, the production of the same component by different people, makes peer production more innovative, robust and resilient.

Commons-based peer production is further limited not by the total cost or complexity of a project, but by its modularity and granularity. Modularity is the degree to which a project can break down into smaller components that can be independently and asynchronously produced and recombined. The higher the degree of modularity, the bigger the autonomy and flexibility of peer production. Granularity refers to the size of each module in terms of the time and effort needed to produce it. The smaller the size, the more people are likely to participate in peer production.

The remaining obstacle to peer production is the cost of integration, that is, firstly, the filtering out of incompetent and malign actors and, secondly, the combination of the modules into a whole. Commons-based peer production solves this problem by a combination of four mechanisms: iterative and modular peer production of the integration function itself (moderation and metamoderation on Slashdot); technical solutions embedded in the collaboration platform (Slashdot, Nasa Clickworkers project, Kuro5hin); norm-based social organisation (limited-access commons, Wikipedia, Kuro5hin); and limited reintroduction of hierarchy or market to provide the integration function alone without appropriating the full value of the product (IBM, Linux Kernel, Apache) (Benkler 2002a, 436-443). Benkler puts it very succinctly:

Where the physical capital requirements of a project are either very low, or capable of fulfillment by utilizing pre-existing distributed capital endowments, where the project is susceptible to modularization for incremental production pursued by diverse participants, and where the diversity gain from harnessing a wide range of experience, talent, insight, and creativity in innovation, quality, speed, or precision of connecting outputs to demand is high, peer production can emerge and outperform markets and hierarchies (Benkler 2016b, 10-11).

Interestingly, Benkler argues that integration could provide the opportunity for the creation of peer-based/co-operative models for monetary appropriation, allowing contributors to share the benefits of large-scale service projects, rather than relegating them to individual indirect appropriation (Benkler 2002a, 443). To some degree, this early speculation has come to fruition today. Several cases testify to the rise of platform co-operativism, which is a newly-born business model referring to co- 
operatively-owned, democratically-governed enterprises that use a protocol, website or mobile app to facilitate the sale of goods and services (Scholz 2016a; 2016b). In addition, blockchain technology arguably has the potential to enhance Commonsbased peer production, since it can mutatis mutandis provide a software framework, capable of supporting decentralisation, democratic self-governance and distribution of value (De Filippi and Hassan 2016). However, all these are still experiments and working hypotheses that need to be tested empirically in the long term if they are to sustain an institutional alternative to market and state operation.

To sum up, commons-based peer production is an information, innovation and knowledge production system that, under certain conditions, bears an organisational advantage over firms, governments and pure market clearance. Its success has additional implications for politics and economics. It requires that we reformulate our conceptions about motivations and incentives; it recalibrates the role of property and contract in the domains of information-dependent production and innovation; and it requires adaptations to the theory of the firm and organisational management (Benkler 2016b, 2). What would, therefore, be the role of firms, governments and markets in relation to the potential future development of commons-based peer production?

\section{Expanding the Scope of Commons-Based Peer Production}

One plausible scenario is that firms would continue to prevail on conditions of high capital costs and rent-extraction opportunities that give an advantage over firmhosted or commons-based peer production. The role of firms in innovation becomes then contingent and path-dependent, rather than efficiency or growth-oriented (Benkler 2016a, 7). Firms might move also from information product-based business models to information-embedding material products and service-based business models, thereby shifting towards firm-hosted peer production. A third scenario would be the transition from firm-hosted peer production to a broader collaborative economy that embraces peer production more openly by adopting a co-operative model based on sustainability and reciprocity (Benkler 2016a, 8).

A number of thinkers have built on the third scenario. Adam Arvidsson and Nikolai Peitersen (2013) illustrate an ethical economy of productive publics, consisting in collaborative networks of peer producers, supported by the Internet and mobile applications. Commons-based peer production could enhance an economic democracy in which the universal measure of value would be the general sentiment. Arvidsson and Peitersen demonstrate a technologically advanced Habermasian transformation of the public sphere, which would open up a more rational and democratic negotiation of economic value, bringing together politics, the commons and a reformed capitalism. Johan Söderberg (2008) envisages a hacker movement expanding into commons-based peer production, thus subverting capitalism. De Angelis (2017) develops a post-capitalist version of the commons based on a Marxist-feminist political economy. Douglas Rushkoff (2016) introduces a hybrid business model of co-operation between corporations and the commons in the form of a "benefit corporation" where the pursuit of growth is subsumed to a sustainable economy based on value creation and the recycling of money. The "benefit corporation" model would be framed by nonprofit and social enterprises, crowdfunding, local currencies, time banks and platform co-operatives built on blockchain protocols. In a similar vein, Kostakis and Bauwens develop a model of open co-operativism between commons-based peer production, ethical market entities and a partner state (Kostakis and Bauwens 2014). 
In all above scenarios, the role of government remains crucial. From the standpoint of a law scholar, Benkler emphasises the issue of property rights. As mentioned above, his main argument is that strong intellectual property rights are detrimental to innovation and knowledge/information production. They harm peer production by raising the cost of access to information, thereby limiting the barriers for hundreds of thousands who could otherwise contribute without violating the rights of the owner of the information input. Therefore, the state would do better to enhance commonsbased licensing rather than strengthening intellectual property rights (Benkler 2002a, 444-446; Benkler 2001; Benkler 2002b). Benkler does not limit the role of governments to the regulation of the copyright system. He favours a liberal state that plays constructive roles in the networked information economy. Some examples are the municipal funding of neutral broadband networks, state funding of basic research, and possible strategic regulatory interventions to negate monopoly control over essential resources in the digital environment (Benkler 2006, 21).

However, the relation of commons-based peer production to state and market operation remains somewhat vague in Benkler's, work given his ambivalence over the scope of commons-based peer production, indicating a tension between his liberal commitments and anarchistic visions. This tension reflects a deeper lacuna in his work, revealing the absence of a strategy as to how the digital commons can replicate itself into the material Commons and control as much as possible of the world economy.

In this respect, De Angelis's critique of Benkler that the immaterial production of the digital commons depends crucially on material production is valid (De Angelis and Pedersen 2010). Software and hardware need energy and minerals in their industrial production, while software developers themselves need to eat, rest and reproduce. Both resources and agents are conditioned by capitalist social structures shaping politics, the market and civil society at large. Thus, the absence of a strategy to expand the digital commons into material production hinders the control of the world economy as much as possible, as Benkler's anarchistic visions would suggest.

But De Angelis himself does not offer a concrete alternative. In his latest work, he portrays a post-capitalist vision of commons-based peer production (De Angelis 2017). He introduces the mechanisms of "boundary commoning" and "structural coupling" to boost, respectively, the internal co-operation between different commons and the making of external deals with capital, both allowing the commons to expand within capitalism and to reach a critical mass on a mission to bring about a "middle class explosion". Drawing on systems theory, cybernetics and Marxist-feminist political economy, he develops a tautological version of the commons movement supposed to gradually outflank the state and capital by reducing the power of the latter to regulate the complexity and variety of the former. Put simply, De Angelis argues that the commons will grow by creating common wealth that will allow it to interlace, multiply and outpace the state and capital. The big issue is, however, how to create the common wealth necessary for the multiplication of the commons given the high dependence of the commons on the state and capital. De Angelis acknowledges the deep relation of the commons movement to law, politics and the media. Yet he does not provide any concrete proposal as to how this relation could develop in the interests of the commons.

De Angelis has successfully conceptualised the fine line between material and immaterial production, emphasising the reproduction basis of the commons: food, care, energy, housing, education, social relations. However, he does not offer a solu- 
tion as to how the immaterial production of digital commons can connect to material commons-based peer production and reproduce the commons in the long run.

Bauwens and Kostakis have the ambition to fill this gap in the literature. Similarly to De Angelis, they advocate a sort of capitalist commons, that is, commons developing in co-operation with a friendly capitalism willing or forced to adjust to commonsbased peer production in the long run. Some examples are a number of companies active in FOSS development such as the Linux Professional Institute, the Mozilla corporation, Red Hat, Endless, SUSE, Wikia company, Automatic company, Enspiral, Sensorica, and more (Bauwens et al. 2017). The advantage of Bauwens and Kostakis's work over De Angelis's is that they develop a more concrete and coherent strategy on a mission to advance commons-based peer production vis-à-vis capital and the state.

Bauwens and Kostakis introduce the "Design Global - Manufacture Local" (DG$\mathrm{ML}$ ) model to connect local commons (limited-access/material commons) to global commons (digital/immaterial Commons) (Kostakis et al. 2016). In a nutshell, DG-ML follows the logic that what is not scarce becomes global (i.e. global commons of knowledge, design, software), and what is scarce (i.e. hardware) becomes local. Global (digital) commons connect to local commons via Transition Towns, decentralised communities and fablabs/makerspaces based on free/open source software/hardware and renewable energy systems distributed through microgrids on blockchain and the Internet of Things. 3D printers, open source hardware (i.e. Arduino), laser cutters, and CNC machines help connect open source code to design and manufacture. Thus, the DG-ML model introduces an on-demand distributed mode of production that has significant advantages over capitalist production: (1) it lowers production costs (no patent costs, no transportation and maintenance costs, no planned obsolescence); (2) it democratises production by unleashing new forms of collaboration and techno-social innovation; (3) it contributes to a sustainable and resilient society and economy (Kostakis et al. 2015, 126). A number of illustrative case studies have been documented in the literature so far: L'Atelier Paysan (AP), Farm Hack (FH), Ability-Mate, Wikihouse, RepRap, Osvehicle and OpenBionics (Kostakis et al. 2016).

These are all still limited cases that need to expand and be tested empirically in the long term, before they crystallise into a sustainable economic model of commonsbased peer production. Kostakis and Bauwens recognise that the DG-ML model alone cannot challenge capitalism. For this reason, they incorporate the DG-ML model on a broader ecosystem of open co-operativism that consists of three interrelated components: (1) the civil society of commons-based peer production; (2) ethical market entities aligning around commons-based peer production; and (3) a Partner State supporting win-win partnerships between civil society and ethical market entities (Kostakis and Bauwens 2014). Kostakis and Bauwens argue for the creation of a diversity of institutions - including a partner state - built around commons-based peer production for the purpose of sustaining a counter-hegemonic power against predatory capitalism and neoliberalism. In this framework, the role of the state is not limited to calibrating the space between markets and peer production by loosening up strong intellectual property rights, as noted by Benkler, but expands into creating the conditions for a long-term commons transition. The state becomes a commons state rather than a liberal or social democratic state.

In contrast to Benkler's optimism over the prospects of Commons-based licensing, Bauwens and Kostakis are vigilant against the actual co-optation of cybercommunism by platform capitalism. They argue that the more communist the sharing li- 
cense, the more capitalist the practice (Bauwens and Kostakis 2014). And this is, indeed, what we have witnessed occurring in FOSS production during the last two decades (Birkinbine 2018). This does not diminish the fact that firm-hosted peer production allows for hundreds of thousands of developers to collaborate globally in a decentralised manner. Such collaboration does not prevent, however, corporations rendering peer production into a precarious model of subsistence for the majority of participants. To reverse this, Bauwens and Kostakis introduce a Peer Production/Copyfair License (PPL), first designed and proposed by Kleiner (2010), that differs both from the GPL and the Creative Commons License in that it allows the commercialisation of one's work rather than a more agile copyright protection. Instead of capital capturing the use value of the Commons by means of the GPL (ex. IBM), the PPL allows for the commercialisation of commons resources and knowledge in exchange for reciprocity (material or immaterial) or rent. The goal here is to introduce reciprocity in the market. Additionally, a stream of income could be directed from ethical market entities to the commons, thus securing the sustenance of the Commons.

Yet Bauwens and Kostakis's account of commons-based peer production does not come without deficiencies. Despite the fact that they develop a more detailed, coherent and concrete strategy compared to De Angelis, they stick at times to a technocratic and economistic vision of the commons. They need instead to envision a more holistic self-institutionalisation of the commons, encompassing all the major social systems (law, politics and the media) along with the reproduction basis of the commons highlighted by De Angelis: care, energy, food, housing, education, morals. Both in Benkler's and Bauwens and Kostakis's work, there is a lack of the political dimension, which is reduced to legalistic and eco-techy hacks. Their work requires a more vibrant political spin to form an inter-compatible strategy aiming to reach a critical mass. This is not to say that an overall strategy for a commons-oriented societal transition is due to the work of single thinkers. Rather, it demands a commons alliance of multiple agents, including citizens, activists, researchers, institutions and political parties across the globe. In particular, human computer interaction and digital platform design deal with complex issues of political theory, embedded in algorithmic design, the examination of which is still nascent both empirically and normatively. The research on how social relations are shaped by information and communication technologies and how the latter relate to our social systems and institutions is still preliminary.

Some of the big challenges lying ahead in commons-based peer production are questions of how to tackle issues of concentration of power and conflict; how to reconcile individuality and pluralism with community and unity; how to combine hierarchy and competition with self-management and co-operation; how to untangle the interweaving of meanings and practices across diverse social imaginaries; how to coordinate dispersed, peer-to-peer initiatives; and how to relate to established social systems and power relations in the market, the state and civil society at large. The scope of commons-based peer production is evidently a work in progress.

\section{Conclusion}

This article aims to critically examine the conceptualisation of "commons-based peer production" in the work of Yochai Benkler. Commons-based peer production refers to a non-market sector of information, knowledge and cultural production, not treated as private property but as an ethic of open sharing and co-operation. Benkler has focused his work particularly on the digital commons as it develops on the Internet and 
FOSS. The digital commons consist of open contributory networks of distributed or collective tasks, set and executed by groups online in a decentralised and autonomous fashion.

I made the case that a tension arises between Benkler's liberal commitments and his anarchistic vision for commons-based peer production. Benkler limits the scope of commons-based peer production to the immaterial production of the digital commons, while paradoxically envisaging the control of as much as possible of the world economy by commons-based peer production. This tension reflects a deeper lacuna in his work, revealing the absence of a strategy as to how the immaterial production of the digital commons can connect to material production.

De Angelis's critique of Benkler highlights the indisputable fact that the immaterial production of the digital commons depends on the material production of energy, raw materials and labour. But he cannot provide a technological link between immaterial and material production.

Bauwens and Kostakis introduce the "Design Global-Manufacture Local" model to connect local commons (limited-access/material commons) with global commons (digital/immaterial commons). The crux of their argument is that the digital commons can replicate itself today into material production through the Internet and digital platforms. 3D printers, open source hardware (i.e. Arduino), laser cutters, and CNC machines help connect open source code to design and manufacture through communities, transition towns, fablabs, and so on. They incorporate the DG-ML model on a broader ecosystem of open co-operativism, which consists of a diversity of institutions built around commons-based peer production with the mission of sustaining a counter-hegemonic power against predatory capitalism and neoliberalism.

Yet Bauwens and Kostakis's account of commons-based peer production does not come without deficiencies. They stick to a technocratic and economistic vision of self-institutionalisation that limits the scope of open co-operativism. Both in Benkler's and Bauwens and Kostakis's work, there is a lack of the political dimension, which is necessary to deal with the moral and social implications emerging at the intersection of technology, society, and politics.

\section{References}

Arvidsson, Adam and Nicolai Peitersen. 2013. The Ethical Economy: Rebuilding Value After the Crisis. New York: Columbia University Press.

Arrow, Kenneth. 1962. Economic Welfare and the Allocation of Resources for Invention. In The Rate and Direction of Inventive Activity, edited by Richard Nelson, 609-625. Princeton: Princeton University Press.

Bauwens, Michel and Vasilis Kostakis. 2014. From the Communism of the Capital to Capital for the Commons: Towards an Open Co-operativism. tripleC: Communication Capitalism \& Critique. Open Access Journal for a Global Sustainable Information Society 12 (1): 356361.

Bauwens, Michel, Vasilis Kostakis, Stacco Troncoso and Anna Marie Utratel. 2017. Commons Transition and P2P: a Primer. Amsterdam: Transnational Institute.

Benkler, Yochai. 2016a. Peer Production, the Commons, and the Future of the Firm. Strategic Organization 15 (2): 264-274.

Benkler Yochai, 2016b. Peer Production and Cooperation. In Handbook on the Economics of the Internet, edited by Johannes Bauer and Michael Latzer. Cheltenham: Edward Elgar.

Benkler, Yochai. 2013. Practical Anarchism: Peer Mutualism, Market Power, and the Fallible State. Politics \& Society 41 (2): 213-251.

Benkler, Yochai. 2011a. Networks of Power, Degrees of Freedom. International Journal of Communication 5: 721-755. 
Benkler, Yochai. 2011b. The Penguin and the Leviathan: The Triumph of Cooperation Over Self-Interest. New York: Crown Business.

Benkler, Yochai. 2006. The Wealth of Networks: How Social Production Transforms Markets and Freedom. New Haven: Yale University Press.

Benkler, Yochai. 2002a. Coase's Penguin, or, Linux and the Nature of the Firm. The Yale Law Journal 112 (3): 349-466.

Benkler, Yochai. 2002b. Intellectual Property and the Organization of Information Production. International Review of Law and Economics 22 (1): 81-107.

Benkler, Yochai. 2001. The Battle over the Institutional Ecosystem in the Digital Environment. Communications of the ACM 44 (2): 84-90.

Benkler, Yochai, Aaron Shaw and Benjamin Mako Hill. 2015. Peer Production: A Form of Collective Intelligence. In Handbook of Collective Intelligence, edited by Thomas Malone and Michael Bernstein. Cambridge, MA: MIT Press.

Birkinbine, Ben. 2018. Commons Praxis: Towards a Critical Political Economy of the Digital Commons. tripleC: Communication Capitalism \& Critique. Open Access Journal for a Global Sustainable Information Society 16 (1): 290-305.

Bowles, Samuel and Hwang Sung-Ha. 2008. Social Preferences and Public Economics: Mechanism Design when Social Preferences Depend on Incentives. Journal of Public Economics 92 (8-9): 1811-1820.

Bowles, Samuel and Sandra Polanía-Reyes. 2012. Economic Incentives and Social Preferences: Substitutes or Complements? Journal of Economic Literature 50 (2): 368-425.

Broumas, Antonis. 2017. Social Democratic and Critical Theories of the Intellectual Commons: A Critical Analysis. tripleC: Communication Capitalism \& Critique. Open Access Journal for a Global Sustainable Information Society 15 (1): 100-126.

Brown, Wendy. 2015. Undoing the Demos: Neoliberalism Stealth Revolution. New York: Zone Books.

Bryant, Susan, Andrea Forte and Amy Bruckman. 2005. Becoming Wikipedian: Transformation of Participation in a Collaborative Online Encyclopedia. In Proceedings of the 2005 International ACM SIGGROUP Conference on Supporting Group Work, GROUP '05, 110. New York: ACM.

Camerer, Colin and Ernst Fehr. 2004. Measuring Social Norms and Preferences Using Experimental Games: A Guide for Social Scientists. In Foundations of Human Sociality: Economic Experiments and Ethnographic Evidence from Fifteen Small-Scale Societies, edited by Joseph Henrich, Robert Boyd, Samuel Bowles, Colin Camerer, Ernst Fehr and Herbert Gintis, 55-95. Oxford: Oxford University Press.

Coleman, Gabriella. 2004. The Political Agnosticism of Free and Open Source Software and the Inadvertent Politics of Contrast. Anthropological Quarterly 77 (3): 507-519.

De Angelis, Massimo. 2017. Omnia Sunt Communia. On the Commons and the Transformation to Postcapitalism. London: Zed Books.

De Angelis, Massimo and J. Martin Pedersen. 2010. Property, Commoning and the Politics of Free Software. Special Issue, thecommoner 14: 9-295.

De Filippi, Primavera. 2015a. Community Mesh Networks: Citizens Participation in the Deployment of Smart Cities. In Social, Economic, and Environmental Sustainability in the Development of Smart Cities, edited by Andrea Vesco and Francesco Ferrero, 298-314. Hershey, PA: IGI Global.

De Filippi, Primavera. 2015b. Translating Commons-based Peer Production Values into Metrics: Towards Commons-based Cryptocurrencies. In Handbook of Digital Currency, edited by David Lee Kuo Chuen, 463-48. London: Elsevier.

De Filippi, Primavera and Samer Hassan. 2016. Blockchain Technology as a Regulatory Technology: From Code is Law to Law is Code. First Monday 21 (12).

De Filippi, Primavera and Félix Tréguer. 2015a. Expanding the Internet Commons: The Subversive Potential of Wireless Community Networks. Journal of Peer Production 6: Disruption and the Law, January. 
De Filippi, Primavera and Félix Tréguer. 2015b. Wireless Community Networks: Towards a Public Policy for the Network Commons. In Net Neutrality Compendium: Human Rights, Free Competition and the Future of the Internet, edited by Luca Belli and Primavera De Filippi, 261-270. New York: Springer.

De Filippi, Primavera and Peter Troxler. 2016. From Material Scarcity to Artificial Abundance: The Case of FabLabs and 3D Printing Technologies. In 3D Printing: Legal, Philosophical and Economic Dimensions, edited by Bibi van den Berg, Simone van der Hof and Eleni Kosta, 65-83. The Hague: T.M.C. Asser Instituut.

Fehr, Ernst and Herbert Gintis. 2007. Human Motivation and Social Cooperation: Experimental and Analytical Foundations. Annual Review of Sociology 33: 43-64.

Frey, Bruno. 1997. A Constitution for Knaves Crowds Out Civic Virtues. The Economic Journal 107 (443): 1043-1053.

Frey, Bruno and Reto Jegen. 2001. Motivation Crowding Theory. Journal of Economic Surveys 15 (5): 589-611.

Forte, Andrea and Amy Bruckman. 2008. Scaling Consensus: Increasing Decentralization in Wikipedia Governance. In Proceedings of the 41st Annual Hawaii International Conference on System Science, 157. IEEE.

Hardin, Garrett. 1968. The Tragedy of the Commons. Science 162: 1243-1248.

Kleiner, Dimitry. 2010. The Telecommunist Manifesto. Amsterdam: Institute of Network Cultures.

Kostakis, Vasilis and Michel Bauwens. 2014. Network Society and Future Scenarios for a Collaborative Economy. London: Palgrave Macmillan.

Kostakis, Vasilis, Kostas Latoufis, Minas Liarokapis and Michel Bauwens. 2016. The Convergence of Digital Commons with Local Manufacturing from a Degrowth Perspective: Two Illustrative Cases. Journal of Cleaner Production 197 (2): 1684-1693. http://doi.org/10.1016/j.jclepro.2016.09.077

Kostakis, Vasilis, Vasilis Niaros, George Dafermos and Michel Bauwens. 2015. Design Global Manufacture Local: Exploring the Contours of an Emerging Productive Model. Futures 73: 126-135.

Lakhani, Karim and Eric von Hippel. 2003. How Open Source Software Works. Research Policy 32 (6): 923-943.

Lampe, Cliff, Eric Johnston and Paul Resnick. 2007. Follow the Reader: Filtering Comments on Slashdot. In Proceedings of the SIGCHI Conference on Human Factors in Computing Systems, CHI '07, 1253-1262. New York: ACM.

Lampe, Cliff and Paul Resnick. 2004. Slash(dot) and Burn: Distributed Moderation in a Large Online Conversation Space. In Conference on Human Factors in Computing Systems (CHI), 543-550. Vienna: ACM Press.

Lerner, Josh and Jean Tirole. 2002. Some Simple Economics of Open Source. Journal of Industrial Economics 50 (2): 197-234.

Lessig, Lawrence. 2006. Code and Other Laws of Cyberspace. New York: Basic Books.

Lowenberg, Anton D. 1990. Neoclassical Economics as a Theory of Politics and Institutions, Cato Journal 9 (3): 619-639.

Ostrom, Elinor. 1990. Governing the Commons: The Evolution of Institutions for Collective Action. New York: Cambridge University Press.

Ostrom, Elinor and Charlotte Hess. 2007. Private and Common Property Rights. Workshop in Political Theory and Policy Analysis, Indiana University.

Pentzold, Christian. 2011. Imagining the Wikipedia Community: What do Wikipedia Authors Mean When They Write About Their 'Community'? New Media \& Society 13 (5): 704-721.

Quilligan, James B. 2012. Why Distinguish Common Goods From Public Goods? In The Wealth of the Commons, A World Beyond Market and State, edited by David Bolier and Silke Helfrich. Amherst, MA: Levellers Press.

Raymond, Eric. 1999. The Cathedral and the Bazaar. Sebastopol, CA: O'Reilly. 
Reisman, David. 1990. Theories of Collective Action, Downs, Olson and Hirsch. Basingstoke: Palgrave Macmillan.

Rushkoff, Douglas. 2016. Throwing Rocks at the Google Bus: How Growth Became the Enemy of Prosperity. New York: Portfolio/Penguin.

Scholz, Trebor. 2016a. Ours to Hack and to Own, The Rise of Platform Cooperativism, A New Vision for the Future of Work and a Fairer Internet. New York: Or Books.

Scholz, Trebor. 2016b. Platform Cooperativism. Challenging the Corporate Sharing Economy. New York: Rosa Luxemburg Stiftung.

Söderberg, Johan. 2008. Hacking Capitalism, The Free and Open Source Movement. New York: Routledge.

Springer, Simon. 2012. Neoliberalism as Discourse: Between Foucauldian Political Economy and Marxian Poststructuralism. Critical Discourse Studies 9 (2): 133-147.

Stallman, Richard. 2002. Free Software, Free Society. Boston, MA: GNU Press.

von Hippel, Eric. 2005. Democratizing Innovation. Cambridge, MA: MIT Press.

von Hippel, Eric. 1988. The Sources of Innovation. New York: Oxford University Press.

von Krogh, Georg, Sebastian Spaeth, and Karim Lakhani. 2003. Community, Joining, and

Specialization in Open Source Software Innovation: a Case Study. Research Policy, 32 (7): 1217-1241.

Weber, Max. 1978. Economy and Society: An Outline of Interpretive Sociology. Berkeley: University of California Press.

\section{About the Author}

Evangelos Papadimitropoulos

Evangelos Papadimitropoulos holds a Ph.D. in the political philosophy of Cornelius Castoriadis. He is currently a research affiliate at the Free University of Amsterdam. 